\title{
Complex Formation of 1,6-Anhydro- $\beta$-Maltose and Sodium Ions Using Single-Crystal X-Ray Crystallography and NMR Spectroscopy
}

\author{
Takashi Fujimoto ${ }^{1}$, Daisuke Miura', Takayuki Kato ${ }^{1}$, Osamu Kamo ${ }^{2}$, Yuichi Shimoikeda ${ }^{2}$, \\ Tomoya Machinami ${ }^{1}$, Mitsuru Tashiro ${ }^{1}$ \\ ${ }^{1}$ Department of Chemistry, School of Sciences and Engineering, Meisei University, Hino, Japan \\ ${ }^{2}$ Solution \& Marketing Division, JEOL RESONANCE Inc., Akishima, Japan \\ Email: tashiro@chem.meisei-u.ac.jp
}

Received May 15, 2013; revised June 17, 2013; accepted July 15, 2013

Copyright (C) 2013 Takashi Fujimoto et al. This is an open access article distributed under the Creative Commons Attribution License, which permits unrestricted use, distribution, and reproduction in any medium, provided the original work is properly cited.

\begin{abstract}
Complex formation of 1,6-anhydro- $\beta$-maltose and sodium ions was characterized using single-crystal X-ray crystallography and solution- and solid-state NMR spectroscopy. The 7-coordination structure, comprising two 1,6-anhydro$\beta$-maltoses, a thiocyanate ion and a sodium ion, was identified in the crystal of the complex, where a sodium ion was positioned in the center of the pentagon. In the NMR study, the line broadening of ${ }^{23} \mathrm{Na}$ signals and the decrease of the spin-lattice relaxation times $\left(T_{1}\right)$ of ${ }^{23} \mathrm{Na}$ were observed in $\mathrm{CD}_{3} \mathrm{OD}$ in the presence of 1,6 -anhydro- $\beta$-maltose, indicating complex formation.
\end{abstract}

Keywords: 1,6-Anhydro- $\beta$-Maltose; Complex Formation; Single-Crystal X-Ray Crystallography; Solid-State NMR Spectroscopy

\section{Introduction}

The abilities of carbohydrates to form complex with cations have been used in the separation of sugar mixtures and the isolation of single tautomeric forms in solution. One of its application is separation of sugars using cation-exchange chromatography $[1,2]$. For instance, Dglucose and D-fructose were separated using a $\mathrm{Ca}^{2+}$ column [3], and $\alpha$ and $\beta$ anomers of D-allose (both as pyranose and furanose forms) were isolated owing to the difference of ability to coordinate with cations [4]. The structural feature of carbohydrates is hydroxyl groups, which is feasible to form complexes in solution with monovalent cations [5,6]. Electrophoretic studies demonstrated that alkali metal ions were able to form complexes with polyhydroxy compounds. The migration rate of 1,6-anhydro- $\beta$-D-glucopyranose in the presence of metal ion was extremely higher than that alone, indicating complex formation [6].

Our group has been studying the complex formation of alkali metal ions and 1,6-anhydro sugars [7,8], which were prepared from the corresponding free sugars through intramolecular dehydration. In past studies, the complexation of 1,6 -anhydro- $\beta$-maltose with rubidium, which of 1,6-anhydro- $\beta$-D-glucopyranosewith rubidium [9] and which of 1,6-anhydro- $\beta$-maltotriose with potassium [10], was characterized using NMR spectroscopy. Besides these studies, interactions between sucrose and various metal ions were investigated by Rondeau et al. using mid-infrared and ${ }^{13} \mathrm{C}$ NMR spectroscopies $[11,12]$. The crystal structure of the complex formed by two 1,6 -anhydro- $\beta$-maltoses with a peroxide and two sodium ions, $\left[\mathrm{Na}_{2}(1,6 \text {-anhydro- } \beta \text {-maltose })_{2}\left(\mathrm{H}_{2} \mathrm{O}\right)_{3}\right] \mathrm{O}_{2}$, was determined by single-crystal X-ray crystallography [13]. The $\mathrm{O}_{2}$ moiety was identified as a discrete peroxide dianion, whereas two sodium and two carbohydrate molecules constituted a binuclear complex counter cation. The crystal structure of 1,6-anhydro- $\beta$-maltose forming an inclusion complex with a potassium ion was also determined [14]. In the crystal structure, both 8- and 9-coordination forms were identified. The 8-coordination structure, which can be defined as the distorted capped pentagonal bipyramidal structure, comprised two 1,6-anhydro- $\beta$-maltoses, a thiocyanate ion, a methanol and a potassium ion. A potassium ion was positioned in the center of the bipyramidal structure, where two 1,6-anhydro- $\beta$-maltoses, possessing identical conformation, surrounded a potassium ion. The 
9-coordination structure, which can be defined as the capped hexagonal bipyramidal structure, comprised three 1,6 -anhydro- $\beta$-maltoses, a thiocyanate ion and a potassium ion. Although a potassium ion was positioned in the center of the bipyramidal structure as observed in 8-coordination structure, three 1,6 -anhydro- $\beta$-maltoses, possessing identical conformation, surrounded a potassium ion. For the purpose of elucidating the mechanism of 1,6-anhydro sugar-forming complexes with alkali metal ions, we have investigated the complex formation of 1,6-anhydro- $\beta$-maltose (Figure 1) with sodium ions using single-crystal X-ray crystallography and NMR spectroscopy. The crystals of the free form of 1,6-anhydro$\beta$-maltose and those of an inclusion complex with a sodium ion were also used in the analysis of the solid-state NMR spectroscopy.

\section{Experimental}

\subsection{Single-Crystal $X$-Ray Crystallography}

Equal molar amounts of 1,6-anhydro- $\beta$-maltose (324 mg) and $\mathrm{NaSCN}(78.6 \mathrm{mg}$ ) were dissolved in $3 \mathrm{ml}$ methanol, and the solution was kept at room temperature for $48 \mathrm{hr}$. After filtration, a colorless prism, having approximate dimensions of $0.20 \times 0.20 \times 0.20 \mathrm{~mm}$, was mounted in a loop. The 1,6-anhydro- $\beta$-maltose (324 mg) was dissolved in $5 \mathrm{ml}$ methanol, and the solution was kept at room temperature for $48 \mathrm{hr}$. After filtration, a colorless prism, having approximate dimensions of $0.20 \times 0.20 \times 0.20$ $\mathrm{mm}$, was mounted in a loop. All measurements were carried out using a Rigaku RAXIS RAPID imaging plate area detector with graphite monochromated Mo- $K \alpha$ radiation at $123 \mathrm{~K}$. The crystal and experimental data of the 1,6 -anhydro- $\beta$-maltose forming an inclusion complex with a sodium ion and its free form are given in Table 1.

\subsection{Solid-State NMR Spectroscopy}

Crystals of an inclusion complex with a sodium ion and

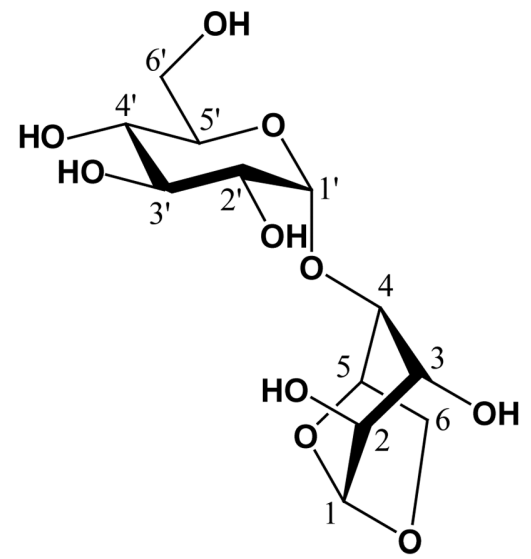

Figure 1. Structure of 1,6-anhydro- $\beta$-maltose.
Table 1. Crystal and experimental data of 1,6-anhydro$\beta$-maltose forming an inclusion complex with a sodium ion and the free form of 1,6 -anhydro- $\beta$-maltose.

\begin{tabular}{|c|c|c|}
\hline & complex & free \\
\hline Formula & $\mathrm{C}_{13} \mathrm{H}_{20} \mathrm{Na}_{1} \mathrm{~N}_{1} \mathrm{O}_{10} \mathrm{~S}_{1}$ & $\mathrm{C}_{24} \mathrm{H}_{42} \mathrm{O}_{21}$ \\
\hline Formula weight & 405.35 & 666.58 \\
\hline Crystal system & monoclinic & triclinic \\
\hline Space group & $P 2_{1} \quad Z=2$ & $P 1 \quad Z=1$ \\
\hline Crystal dimensions (mm) & $0.20 \times 0.20 \times 0.20$ & $0.20 \times 0.20 \times 0.20$ \\
\hline Temperature $(\mathrm{K})$ & 123 & 123 \\
\hline$a(\AA)$ & $8.864(4)$ & $8.323(4)$ \\
\hline$b(\AA)$ & $12.208(4)$ & $9.246(5)$ \\
\hline$c(\AA)$ & $9.010(4)$ & $9.798(4)$ \\
\hline$V\left(\AA^{3}\right)$ & $821.8(6)$ & $685.8(6)$ \\
\hline$D_{\text {calc }}\left(\mathrm{g} / \mathrm{cm}^{3}\right)$ & 1,638 & 1,638 \\
\hline No. of reflections & 9924 & 8255 \\
\hline 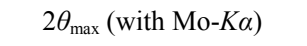 & 60.1 & 60.1 \\
\hline$R$ & 0.0249 & 0.0351 \\
\hline $\begin{array}{l}\text { Max. shift/error in final } \\
\text { cycle }\end{array}$ & 0.000 & 0.000 \\
\hline $\begin{array}{l}\text { Max. peak in final diff. } \\
\text { map }\left(\mathrm{e}^{-} / \AA^{3}\right)\end{array}$ & 0.50 & 1.11 \\
\hline $\begin{array}{l}\text { Min. peak in final diff. } \\
\operatorname{map}\left(\mathrm{e}^{-} / \AA^{3}\right)\end{array}$ & -0.31 & -1.24 \\
\hline Measurements & \multicolumn{2}{|c|}{ R-AXIS RAPID (Rigaku, 2000) } \\
\hline Program system & \multicolumn{2}{|c|}{ Crystal structure 4.0} \\
\hline Structure determination & \multicolumn{2}{|c|}{ SIR2004 [15] } \\
\hline Refinement & \multicolumn{2}{|c|}{ Full-matrix least-squares on $F^{2}$} \\
\hline
\end{tabular}

of the free form of 1,6 -anhydro- $\beta$-maltose, and $\mathrm{NaSCN}$ alone were used for the measurements of the solid-state NMR spectroscopy. The ${ }^{23} \mathrm{Na}$ spectra were acquired on a JNM-ECA600 spectrometer equipped with a $1 \mathrm{~mm}$ CP-MAS probe at a spinning speed of $70 \mathrm{kHz}$. The experimental parameters of ${ }^{23} \mathrm{Na}$ for an inclusion complex were number of scans $=640$, recycle time $=1.0 \mathrm{~s}$, and those for NaSCN alone were number of scans $=256$, recycle time $=3.0 \mathrm{~s}$. The ${ }^{23} \mathrm{Na} T_{1 \rho}$ were measured using a saturation recovery method on a JNM-ECA920 spectrometer equipped with a $4 \mathrm{~mm}$ MQ-MAS probe at a spinning speed of $15 \mathrm{kHz}$. The experimental parameters were number of scans $=8$, recycle time $=1.0 \mathrm{~s}$. The pulse intervals were 15 steps. The ${ }^{13} \mathrm{C}$ CP-MAS spectra were acquired on a JNM-ECA500 equipped with a $4 \mathrm{~mm}$ CP-MAS probe at a spinning speed of $15 \mathrm{kHz}$. The experimental parameters of ${ }^{13} \mathrm{C}$ CP-MAS were number of scans $=319$, recycle time $=1.0 \mathrm{~s}$.

\subsection{Solution-State NMR Spectroscopy}

Conventional ${ }^{1} \mathrm{H},{ }^{13} \mathrm{C}$ and ${ }^{23} \mathrm{Na}$ NMR spectra were acquired on a Varian 600 spectrometer using $250 \mu \mathrm{L}$ sam- 
ple solutions of $30 \mathrm{mM} \mathrm{1,6-anhydro-} \beta$-maltose in the presence and absence of $30 \mathrm{mM} \mathrm{NaSCN}$ and $30 \mathrm{mM}$ $\mathrm{NaSCN}$ alone in $99.9 \% \mathrm{CD}_{3} \mathrm{OD}$ in Shigemi tubes at $30^{\circ} \mathrm{C}$. In preparation of the sample solution of 1,6-anhydro$\beta$-maltose in the presence of $\mathrm{NaSCN}$, crystals of an inclusion complex with a sodium ion were dissolved in $\mathrm{CD}_{3} \mathrm{OD}$. The ${ }^{1} \mathrm{H}$ and ${ }^{13} \mathrm{C}$ assignments were carried out using the conventional $1 \mathrm{D}$ and $2 \mathrm{D}$ NMR techniques. The ${ }^{13} \mathrm{C}$ and ${ }^{23} \mathrm{Na}-T_{1}$ measurements were carried out using the inversion recovery method, and the measurements of ${ }^{1} \mathrm{H}$ diffusion coefficients were carried out as described previously [10].

\section{Results and Discussion}

\subsection{Single-Crystal X-Ray Crystallography}

The crystal structures of 1,6 -anhydro- $\beta$-maltose forming an inclusion complex with a sodium ion and its free form were determined usingsingle-crystal X-ray crystallography (Table 1). In the crystal structure of the complex, the 7-coordination structure, which can be defined as the distorted pentagonal bipyramidal structure, was identified as shown in Figure 2(a). It comprised two 1,6-anhydro- $\beta$-maltoses (designated as anhyro sugars $\mathrm{A}$ and $\mathrm{B}$ ), a thiocyanate ion and a sodium ion. A sodium ion was positioned in the center of the pentagon, where two 1,6 -anhydro- $\beta$-maltoses, possessing identical conformation, surrounded a sodium ion. The sodium ion made close contacts to all oxygen atoms involved in the 7 -coordination structure. Its distances were in the range of 2.40 - $2.68 \AA$ (Table 2). The pentagon comprised O5, $\mathrm{O} 1$ ' and $\mathrm{O} 2$ ' of anhyro sugar $\mathrm{A}$ and $\mathrm{O} 3$ and $\mathrm{O} 6$ of anhyro sugar B. The $\mathrm{O} 2$ of anhyro sugar A and a sulfur atom of a thiocyanate ion corresponded to the peak of each pyramid (Figures 2(a) and (b)). Four of these six oxygen atoms, O2, O3, O5 and O6 were involved in 1,6-anhydro moiety. The tendency forming bipyramidal structures was also identified in the crystal structure of 1,6-anhydro- $\beta$-maltose forming an inclusion complex with a potassiumion [14]. These results indicate the importance of 1,6-anhydro moiety in forming complex with alkali metal ions, and provide an insight into the accommodation pattern of 1,6-anhydro- $\beta$-maltose for an alkali metal ion.

In the crystal structure of the free form of 1,6-anhydro- $\beta$-maltose, asymmetric structures, designated as anhyro sugars A and B, were identified as shown in Figure 2(c). A water molecule was surrounded by three molecules of 1,6-anhydro- $\beta$-maltose, forming the 6-corrdination structure (Figures 2(c) and (d)). The close contacts between an oxygen atom of water and 1,6-anhydro- $\beta$ maltoses are summarized in Table 2. Only two oxygen atoms in 1,6-anhydro-moiety made close contacts to an oxygen atom of water. This structural feature was opposite to the 7-coordination structure identified in the
Table 2. Distances $(\AA)$ around a sodium ion in the crystal structure of the complex and those around an oxygen atom of the water in the crystal structure of the free form of 1,6-anhydro- $\beta$-maltose.

\begin{tabular}{cccc}
\hline \multicolumn{2}{c}{ Complex } & \multicolumn{2}{c}{ Free } \\
\hline Atoms & Distances & Atoms & Distances \\
\hline $\mathrm{Na}{ }^{\circ} \mathrm{O} 2(\mathrm{~A})^{\mathrm{a}}$ & 2.44 & $\mathrm{~W}^{\mathrm{b} \cdots} \mathrm{O} 2(\mathrm{~A})$ & 2.90 \\
$\mathrm{Na}{ }^{\circ} \mathrm{O} 3(\mathrm{~B})$ & 2.68 & $\mathrm{~W}^{\cdots} \mathrm{O}$ (A) & 3.14 \\
$\mathrm{Na}{ }^{\circ} \mathrm{O} 5(\mathrm{~A})$ & 2.49 & $\mathrm{~W}^{\cdots} \mathrm{O} 1^{\prime}(\mathrm{A})$ & 3.09 \\
$\mathrm{Na}{ }^{\circ} \mathrm{O} 6(\mathrm{~B})$ & 2.40 & $\mathrm{~W}^{\cdots} \mathrm{O}^{\prime}(\mathrm{A})$ & 2.73 \\
$\mathrm{Na}{ }^{\circ} \mathrm{O} 1^{\prime}(\mathrm{A})$ & 2.49 & $\mathrm{~W}^{\cdots} \mathrm{O}^{\prime}(\mathrm{B})$ & 2.79 \\
$\mathrm{Na}{ }^{\circ} \mathrm{O} 2^{\prime}(\mathrm{A})$ & 2.49 & $\mathrm{~W}^{\cdots} \mathrm{O}^{\prime}\left(\mathrm{A}^{\prime}\right)$ & 2.76 \\
$\mathrm{Na}{ }^{\circ} \mathrm{SCN}^{-}$ & 3.04 & & \\
\hline
\end{tabular}

a" A" means anhydro sugar A defined in Figures 2(a) and (b). "W"W" means an oxygen atom of the water defined in Figures 2(c) and (d).

crystal structure of the complex.

\subsection{Solid-State NMR Spectroscopy}

The ${ }^{23} \mathrm{Na}$ solid-state spectra were acquired for the crystals of an inclusion complex with a sodium ion and NaSCN alone as shown in Figure 3. The signal resonating at $-0.06 \mathrm{ppm}$ in the free form of $\mathrm{NaSCN}$ could be water (Figure 3(b)), considering the hygroscopic property of NaSCN. The ${ }^{23} \mathrm{Na} T_{1 \rho}$ were $0.649 \mathrm{~s}$ and $6.26 \mathrm{~s}$ for the complex and $\mathrm{NaSCN}$ alone, respectively. Comparisons of ${ }^{23} \mathrm{Na}$ spectra and $T_{1 \rho}$ indicated the various close contacts between ${ }^{23} \mathrm{Na}$ and other nuclei in the inclusion complex. The ${ }^{13} \mathrm{C}$ CP-MAS spectra were acquired for crystals of an inclusion complex of 1,6-anhydro- $\beta$-maltose with a sodium ion and those of its free from (Figure 4). As indicated in the single-crystal X-ray crystallography, the free form adopted asymmetric structures. This structural feature was reflected in the ${ }^{13} \mathrm{C} \mathrm{CP}-\mathrm{MAS}$ spectrum (Figure 4(b)). The signals resonating at 102.2 and 95.6 ppm were assigned as $\mathrm{C} 1$ and $\mathrm{C} 1$ ', respectively, referring the assignments in $\mathrm{CD}_{3} \mathrm{OD}$ (Table 4). Both signals split as doublet, and its chemical shift difference was $0.39 \mathrm{ppm}$. However, this doublet pattern could not clearly be identified in the other ${ }^{13} \mathrm{C}$ signals resonating in the upfield region of $64-75 \mathrm{ppm}$. For instance, the ${ }^{13} \mathrm{C}$ signals resonating in the region of $64-66 \mathrm{ppm}$, corresponding to $\mathrm{C} 6$ and $\mathrm{C} 6$ ', did not show the same splitting pattern. In the ${ }^{13} \mathrm{C} \mathrm{CP}-\mathrm{MAS}$ spectrum of the complex, the singlet pattern was observed for $\mathrm{C} 1$ and $\mathrm{C} 1$ ' (Figure 4(a)), which was expected in consideration of the identical conformation of 1,6 -anhydro- $\beta$-maltose.

\subsection{Solution-State NMR Spectroscopy}

The ${ }^{23} \mathrm{Na}$ NMR spectra were acquired in $\mathrm{CD}_{3} \mathrm{OD}$ in the presence and absence of 1,6-anhydro- $\beta$-maltose (Figure 5). The chemical shifts and half height widths of ${ }^{23} \mathrm{Na}$ 


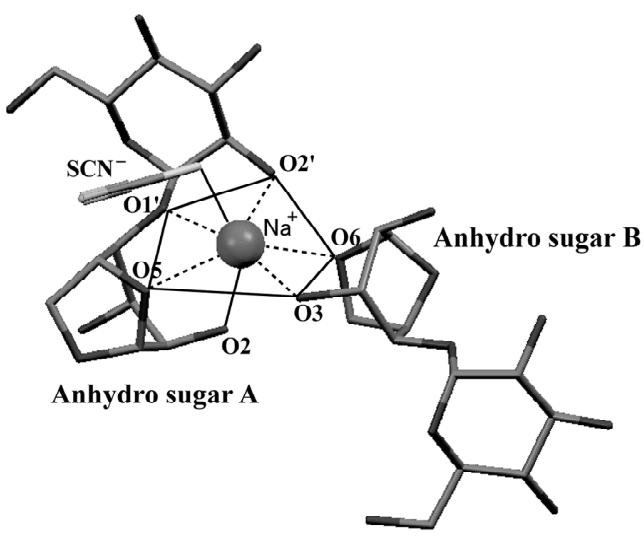

(a)

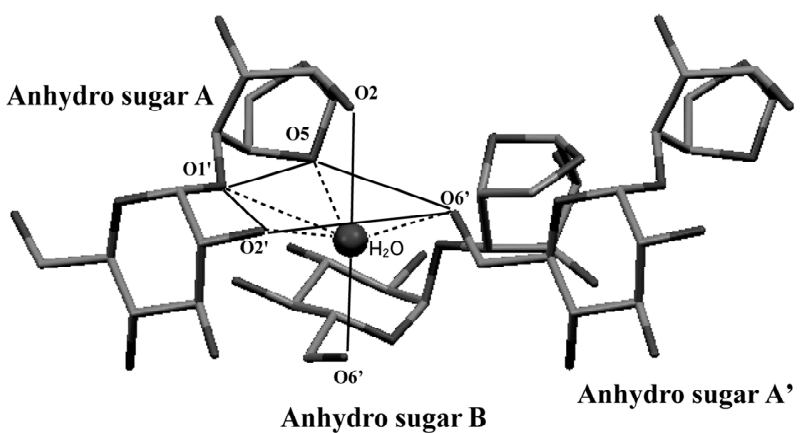

(c)

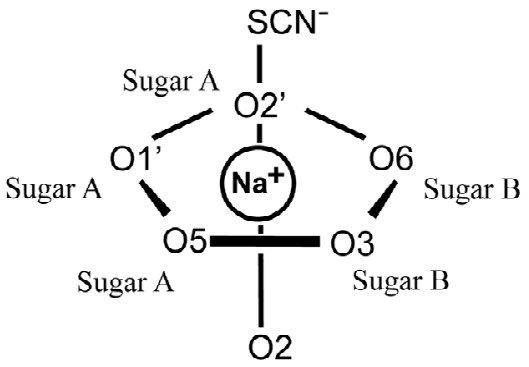

Sugar A

(b)

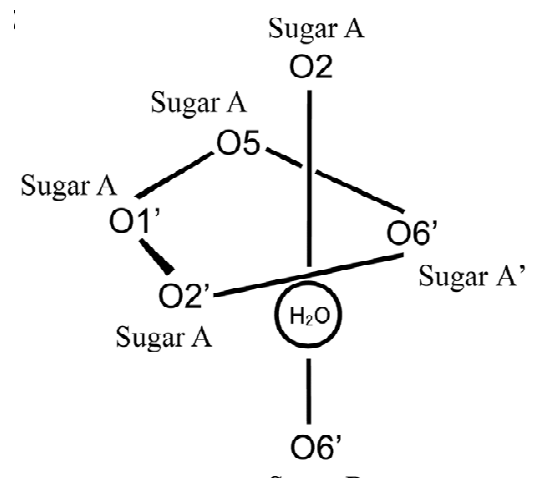

Sugar B

(d)

Figure 2. (a) The crystal structure of 1,6-anhydro- $\beta$-maltose forming an inclusion complex with a sodium ion and (b) its schematic drawing. (c) The crystal structure of the free form of 1,6-anhydro- $\beta$-maltose and (d) its schematic drawing. In (a), close contacts between 1,6-anhydro- $\beta$-maltoses and a sodium ion are shown by dashed lines, and an outline of 7-coordination structure, corresponding to the schematic drawing of (b), is shown by solid lines. In (c), close contacts between 1,6-anhydro- $\beta$-maltoses and an oxygen atom of water are shown by dashed lines, and an outline of 6-coordination structure, corresponding to the schematic drawing of $(\mathrm{d})$, is shown by solid lines.

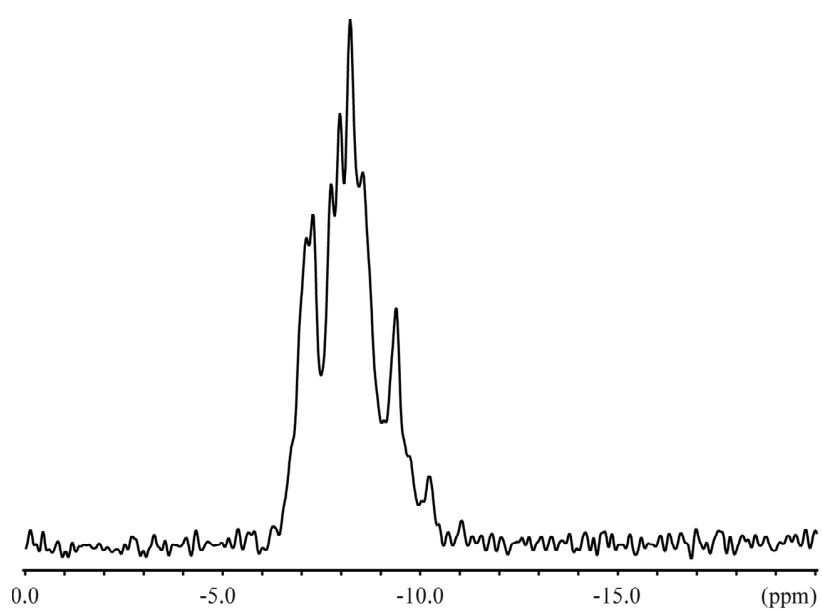

(a)

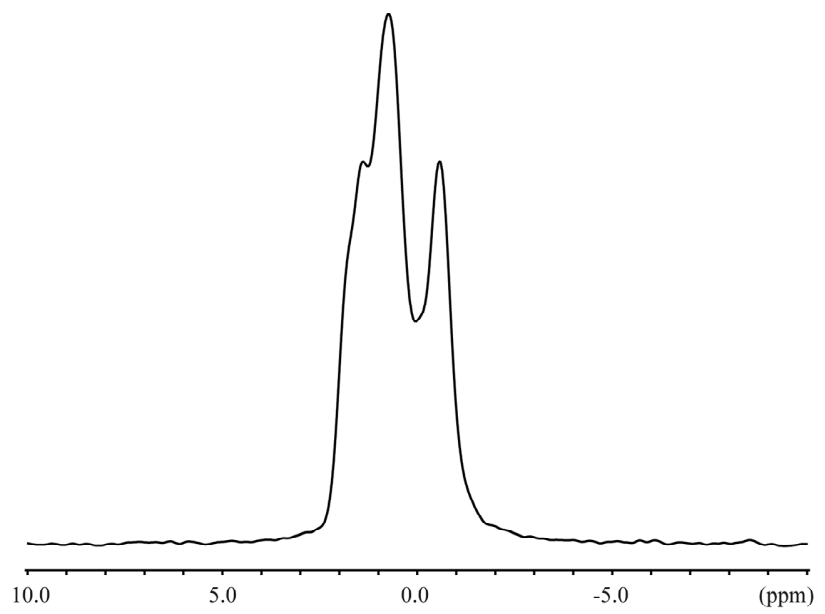

(b)

Figure 3. The ${ }^{23} \mathrm{Na}$ solid-state NMR spectra of the (a) inclusion complex of 1,6 -anhydro- $\beta$-maltose with a sodium ion and (b) NaSCN.

signals in the presence and absence of 1,6-anhydro$\beta$-maltose were $0.748 \mathrm{ppm}$ and $32.3 \mathrm{~Hz}$, and $0.479 \mathrm{ppm}$ and $16.8 \mathrm{~Hz}$, respectively. The significant line broadening was observed in the presence of 1,6-anhydro- $\beta$ - 


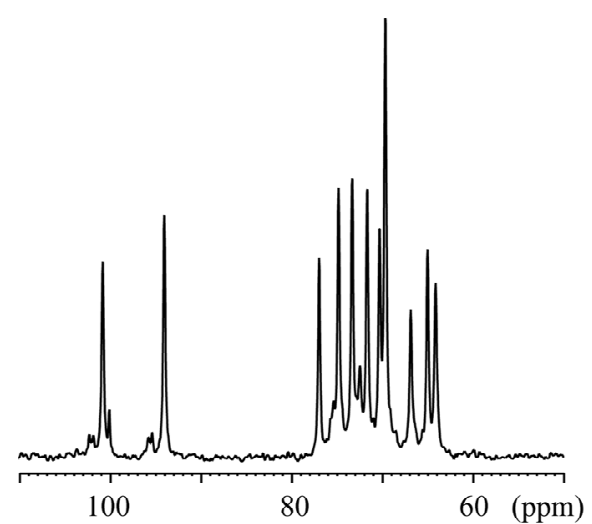

(a)

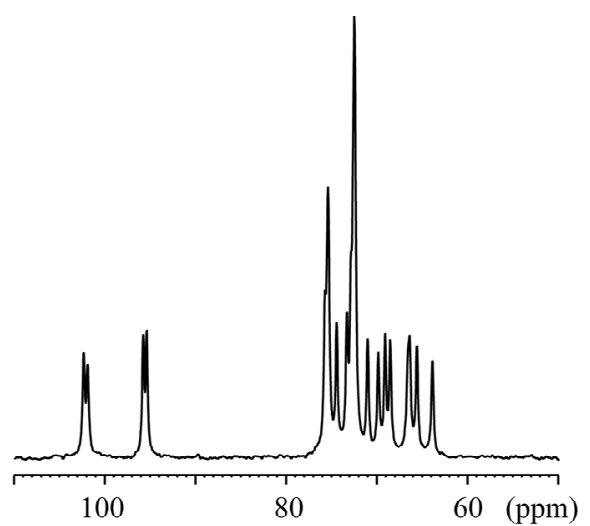

(b)

Figure 4. The ${ }^{13} \mathrm{C}$ CP-MAS NMR spectra of the crystals of the (a) inclusion complex of 1,6 -anhydro- $\beta$-maltose with a sodium ion and (b) free form of 1,6-anhydro- $\beta$-maltose.

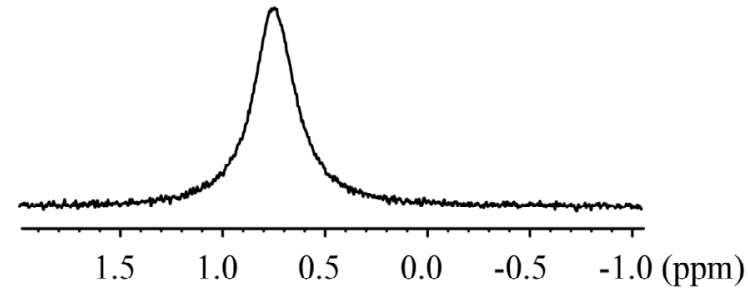

(a)

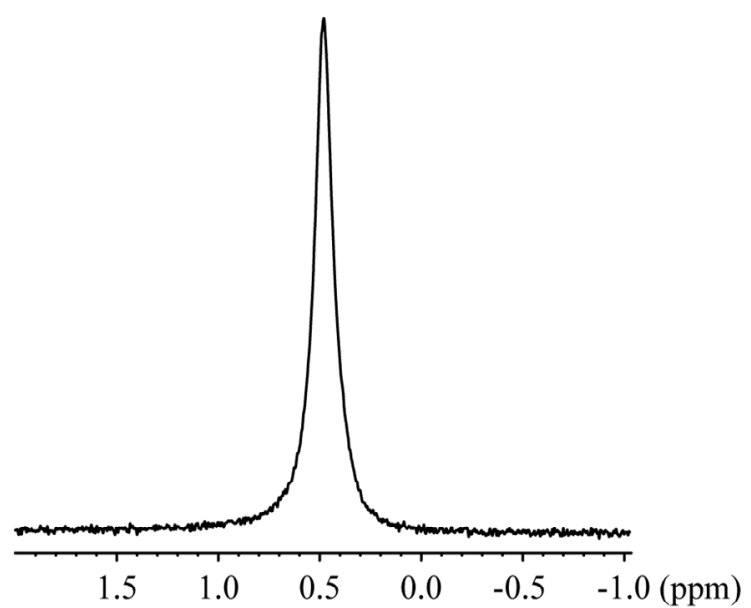

(b)

Figure 5. The ${ }^{23} \mathrm{Na}$ NMR spectra of the (a) inclusion complex of 1,6-anhydro- $\beta$-maltose with a sodium ion and (b) NaSCN in $\mathrm{CD}_{3} \mathrm{OD}$.

maltose. The ${ }^{23} \mathrm{Na}-T_{1}$ values were 9.49 and $21.8 \mathrm{~ms}$ in the aforesaid order. The changes of the half height widths and ${ }^{23} \mathrm{Na}-T_{1}$ unambiguously indicated complex formation of 1,6 -anhydro- $\beta$-maltose with sodium ions in $\mathrm{CD}_{3} \mathrm{OD}$.

The ${ }^{1} \mathrm{H}$ NMR spectra of 1,6 -anhydro- $\beta$-maltose in the presence and absence of $\mathrm{NaSCN}$ are shown in Figures 6(a) and (c). The distinct changes of the spectral pattern were observed in the chemical shift range of $3.24-3.75$ ppm. The maximum difference of ${ }^{1} \mathrm{H}$ chemical shift was $0.04 \mathrm{ppm}$ in $\mathrm{H} 4$, and the overall ${ }^{1} \mathrm{H}$ chemical shift changes were relatively small (Table 3 ). The ${ }^{1} \mathrm{H}$ diffusion coefficients were calculated only for the isolated signals, and ca. $14 \%$ decrease was identified in the presence of NaSCN (Table 3). The diffusion coefficient of a molecule is inversely proportional to the molecular radius, and the lowered diffusion is attributable to the complex formation. The ${ }^{13} \mathrm{C}$ NMR spectra of 1,6-anhydro- $\beta$-maltose in the presence and absence of $\mathrm{NaSCN}$ are shown in Figures 6(b) and (d), and comparisons of ${ }^{13} \mathrm{C}$ chemical shifts and ${ }^{13} \mathrm{C}-T_{1}$ are listed in Table 4 . The ${ }^{13} \mathrm{C}$ chemical shifts of $\mathrm{C} 3$ and $\mathrm{C} 1$ ' were both upfield shifted for $0.7 \mathrm{ppm}$ in the presence of NaSCN. In comparison of ${ }^{13} \mathrm{C}-T_{1}$, a ca. $14 \%$ decrease was observed for $\mathrm{C} 1, \mathrm{C} 2$ and $\mathrm{C} 3$ in the presence of NaSCN (Table 4). The C1, C2 and $\mathrm{C} 3$ are positioned adjacent to the oxygen atoms forming the 7-coordination structure (Figure 2(b)), which could be the reason of affecting its ${ }^{13} \mathrm{C}-T_{1}$. Because the distinct decrease of ${ }^{13} \mathrm{C}-T_{1}$ was identified in a portion of 1,6 -anhydro moiety, the results of ${ }^{13} \mathrm{C}-T_{1}$ studies indicated the importance of the 1,6-anhydro moiety in the complex formation, which was also supported in the analysis of the X-ray crystal structure.

\section{Conclusion}

Complex formation of 1,6 -anhydro- $\beta$-maltose and sodium ions has been elucidated using single-crystal X-ray crystallography and ${ }^{1} \mathrm{H},{ }^{13} \mathrm{C}$ and ${ }^{23} \mathrm{Na} \mathrm{NMR}$ spectroscopy. 


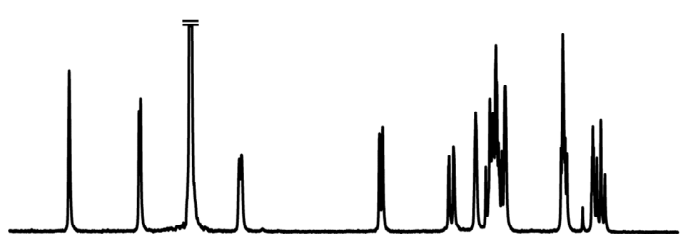

(a)

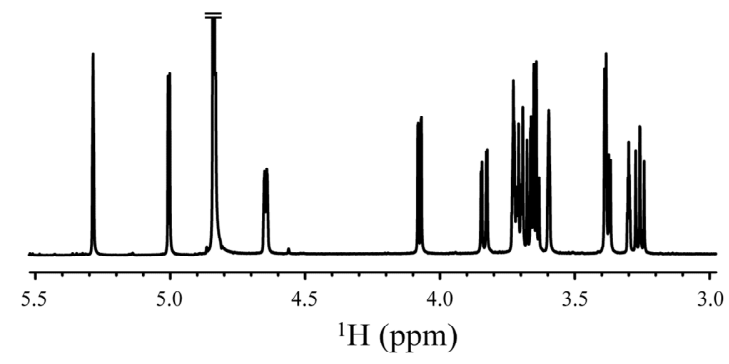

(c)

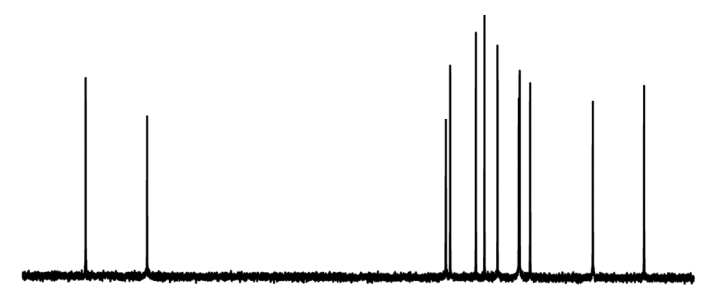

(b)

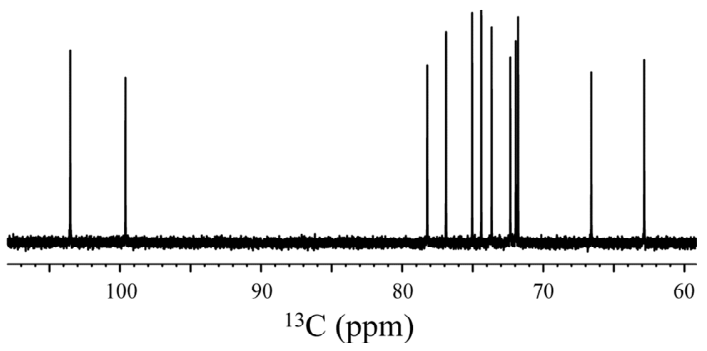

(d)

Figure 6. The ${ }^{1} \mathrm{H}$ and ${ }^{13} \mathrm{C}$ NMR spectra of 1,6 -anhydro- $\beta$-maltose in the $(a, b)$ presence and $(c, d)$ absence of NaSCN in $\mathrm{CD}_{3} \mathrm{OD}$.

Table 3. Comparison of the ${ }^{1} \mathrm{H}$ chemical shifts and ${ }^{1} \mathrm{H}$ diffusion coefficients $(D)$ of 1,6-anhydro- $\beta$-maltose in the presence and absence of NaSCN.

\begin{tabular}{|c|c|c|c|c|c|c|}
\hline & \multicolumn{3}{|c|}{$\delta^{\mathrm{H}} \mathrm{H}(\mathrm{ppm})$} & \multicolumn{3}{|c|}{${ }^{1} \mathrm{H}-D\left(\times 10^{-10} \mathrm{~m}^{2} / \mathrm{s}\right)$} \\
\hline & free & $+\mathrm{NaSCN}$ & $\Delta$ & free & $+\mathrm{NaSCN}$ & ratio \\
\hline $\mathrm{H} 1$ & 5.28 & 5.29 & 0.01 & $6.66 \pm 0.05$ & $5.88 \pm 0.03$ & 0.88 \\
\hline $\mathrm{H} 2$ & 3.39 & 3.41 & 0.02 & & & \\
\hline $\mathrm{H} 3$ & 3.73 & 3.75 & 0.02 & $5.61 \pm 0.02$ & & \\
\hline $\mathrm{H} 4$ & 3.60 & 3.64 & 0.04 & $6.66 \pm 0.04$ & $5.80 \pm 0.01$ & 0.87 \\
\hline H5 & 4.65 & 4.64 & -0.01 & $6.59 \pm 0.03$ & $5.58 \pm 0.02$ & 0.85 \\
\hline H6 & $4.08 / 3.65$ & $4.10 / 3.66$ & $0.02 / 0.01$ & $6.74 \pm 0.06$ & $5.77 \pm 0.02$ & 0.86 \\
\hline $\mathrm{H} 1$ ' & 5.00 & 5.02 & 0.02 & $6.82 \pm 0.08$ & $5.81 \pm 0.04$ & 0.85 \\
\hline $\mathrm{H} 2^{\prime}$ & 3.38 & 3.41 & 0.03 & & & \\
\hline H3' & 3.69 & 3.69 & 0.00 & & & \\
\hline $\mathrm{H} 4^{\prime}$ & 3.26 & 3.26 & 0.00 & $6.79 \pm 0.06$ & $5.73 \pm 0.02$ & 0.84 \\
\hline $\mathrm{H} 5$, & 3.71 & 3.68 & -0.03 & & & \\
\hline H6 & $3.84 / 3.65$ & $3.84 / 3.65$ & $0.00 / 0.00$ & $6.75 \pm 0.06$ & $5.68 \pm 0.02$ & 0.84 \\
\hline
\end{tabular}

Table 4. Comparison of the ${ }^{13} \mathrm{C}$ chemical shifts and ${ }^{13} \mathrm{C}-\mathrm{T}_{1}$ of 1,6 -anhydro- $\beta$-maltose in the presence and absence of NaSCN.

\begin{tabular}{|c|c|c|c|c|c|c|}
\hline & \multicolumn{3}{|c|}{$\delta^{13} \mathrm{C}(\mathrm{ppm})$} & \multicolumn{3}{|c|}{${ }^{13} \mathrm{C}-T_{1}(\mathrm{~s})$} \\
\hline & free & $+\mathrm{NaSCN}$ & $\Delta$ & free & $+\mathrm{NaSCN}$ & ratio \\
\hline $\mathrm{C} 1$ & 103.5 & 103.4 & -0.1 & $0.81 \pm 0.01$ & $0.70 \pm 0.04$ & 0.87 \\
\hline $\mathrm{C} 2$ & 72.3 & 71.9 & -0.4 & $0.80 \pm 0.01$ & $0.68 \pm 0.06$ & 0.85 \\
\hline $\mathrm{C} 3$ & 71.8 & 71.1 & -0.7 & $0.84 \pm 0.02$ & $0.73 \pm 0.04$ & 0.87 \\
\hline $\mathrm{C} 4$ & 78.2 & 77.2 & -1.0 & $0.77 \pm 0.02$ & $0.81 \pm 0.05$ & 1.06 \\
\hline $\mathrm{C} 5$ & 76.9 & 76.9 & 0.0 & $0.72 \pm 0.02$ & $0.77 \pm 0.05$ & 1.07 \\
\hline C6 & 66.6 & 66.5 & -0.1 & $0.46 \pm 0.01$ & $0.45 \pm 0.02$ & 0.99 \\
\hline $\mathrm{C} 1{ }^{\prime}$ & 99.6 & 98.9 & -0.7 & $0.73 \pm 0.01$ & $0.68 \pm 0.03$ & 0.93 \\
\hline $\mathrm{C} 2$ ' & 73.7 & 73.5 & -0.2 & $0.71 \pm 0.01$ & $0.65 \pm 0.04$ & 0.92 \\
\hline $\mathrm{C} 3$ ' & 75.0 & 75.0 & 0.0 & $0.75 \pm 0.01$ & $0.78 \pm 0.07$ & 1.04 \\
\hline $\mathrm{C} 4$ ' & 72.0 & 71.8 & -0.2 & $0.74 \pm 0.01$ & $0.81 \pm 0.05$ & 1.10 \\
\hline $\mathrm{C} 5$ & 74.5 & 74.4 & -0.1 & $0.74 \pm 0.01$ & $0.74 \pm 0.04$ & 1.00 \\
\hline C6' & 62.8 & 62.8 & 0.0 & $0.42 \pm 0.01$ & $0.42 \pm 0.03$ & 0.99 \\
\hline
\end{tabular}


In solution, the comparisons of ${ }^{1} \mathrm{H}$ diffusion coefficients and ${ }^{23} \mathrm{Na}-T_{1}$ unambiguously indicated complex formation, and ${ }^{13} \mathrm{C}$ NMR studies indicated importance of 1,6-anhydro moiety in the complex formation. A contribution of 1,6-anhydro moiety was also recognized in the 7-corrdination structure identified in the single-crystal X-ray structure.

\section{Supplementary Data}

Crystallographic data, excluding structure factors, have been deposited with the Cambridge Crystallographic Data Centre as supplementary publication with CCDC No. 927906 and 922475 for the free form of 1,6-anhydro$\beta$-maltose and its complex with $\mathrm{NaSCN}$, respectively. Copies of the data can be obtained free of charge on application with the Director, CCDC, 12 Union Road, Cambridge CB2 1EZ, UK (fax +44-1223-336-033; e-mail: deposit@ccdc.cam.ac.uk).

\section{Acknowledgements}

The authors wish to thank Dr. M. Nakano for measuring ${ }^{23} \mathrm{Na}-T_{1 \rho}$. This work was partly supported by Nanotechnology Platform Program (Molecule and Material Synthesis) of the Ministry of Education, Culture, Sports, Science and Technology (MEXT), the Joint Studies Program of the Institute for Molecular Science (IMS), Japan. This work was also supported by an Ito Science Foundation and a Grant-in-Aid for Scientific Research (No. 21550092 and 24550108 for M.T.) from the Ministry of Education, Culture, Sports, Science, and Technology.

\section{REFERENCES}

[1] S. J. Angyal, "Complexes of metal cations with carbohydrates in solution," Advances in Carbohydrate Chemistry \& Biochemistry, Vol. 47, 1989, pp. 1-43. doi:10.1016/S0065-2318(08)60411-4

[2] B. Gyurcsik and L. Nagy, "Carbohydrates as Ligands: Coordination Equilibria and Structure of the Metal Complexes," Coordination Chemistry, Vol. 203, No. 1, 2000, pp. 81-149. doi:10.1016/S0010-8545(99)00183-6

[3] P. E. Barker and S. Thawait, "Separation of Fructose from Carbohydrate Mixtures by Semi-Continuous Chromatography," Chemistry and Industry (London), Vol. 21, 1983, pp. 817-821.

[4] S. J. Angyal, G. S. Bethell and R. J. Beveridge, "The Separation of Sugars and of Polyols on Cation-Exchange Resins in the Calcium Form," Carbohydrate Research, Vol. 73, No. 1, 1979, pp. 9-18. doi:10.1016/S0008-6215(00)85471-3

[5] M. D. Diaz and S. Berger, "Studies of the Complexation of Sugars by Diffusion-Ordered NMR Spectroscopy," Carbohydrate Research, Vol. 329, No. 1, 2000, pp. 1-5. doi:10.1016/S0008-6215(00)00239-1

[6] K. F. Morris, P. Stilbs and C. S. Johnson, Jr. "Analysis of
Mixtures Based on Molecular Size and Hydrophobicity by Means of Diffusion-Ordered 2D NMR," Analytical Chemistry, Vol. 66, No. 2, 1994, pp. 211-215. doi: $10.1021 / \mathrm{ac} 00074 \mathrm{a} 006$

[7] C. Schuerch, "Synthesis and Polymerization of Anhydro Sugars," Advances in Carbohydrate Chemistry \& Biochemistry, Vol. 39, 1981, pp. 157-212. doi:10.1016/S0065-2318(08)60206-1

[8] T. Tanaka, W. C. Huang, M. Noguchi, A. Kobayashi and S. Shoda, "Direct Synthesis of 1,6-Anhydro Sugars from Unprotected Glycopyranoses by Using 2-Chloro-1,3-Dimethylimidazolinium Chloride," Tetrahedron Letters, Vol. 50, No. 18, 2009, pp. 2154-2157. doi:10.1016/j.tetlet.2009.02.171

[9] T. Fujimoto, S. Sakuraki, A. Tsutsui, K. Furihata, T. Machinami and M. Tashiro, "Observation of 1,6-anhydro$\beta$-D-Maltose and 1,6-Anhydro- $\beta$-D-Glucopyranosecomplexed with Rubidium by NMR Spectroscopy and Electrospray Ionization Mass Spectrometry," Analytical Sciences, Vol. 21, No. 10, 2005, pp. 1245-1247. doi:10.2116/analsci.21.1245

[10] T. Kato, K.Tsubono, O.Kamo, T. Kato, K. Furihata, T. Fujimoto, T. Machinami and M. Tashiro, "Characterization of the Complex Formation of 1,6-Anhydro- $\beta$-Maltotriose with Potassium using ${ }^{1} \mathrm{H}$ and ${ }^{39} \mathrm{~K}$ NMR Spectroscopy," Magnetic Resonance in Chemistry, Vol. 47, No. 11, 2009, pp. 948-952. doi:10.1002/mrc.2495

[11] P. Rondeau, S. Sers, D. Jhurry and F. Cadet, "Sugar Interac- tion with Metals in Aqueous Solution: Indirect Determi- nation from Infrared and Direct Determination from Nu- clear Magnetic Resonance Spectroscopy," Applied Spectroscopy, Vol. 57, No. 4, 2003, pp. 466-472. doi:10.1366/00037020360626023

[12] P. Rondeau, D. Jhurry, S. Sers and F. Cadet, "Study of the Interactions between Sucrose and Metal Ions $(\mathrm{Mg} 2+$ and $\mathrm{K}+$ ) and Their Simultaneous Quantification in Ternary Mixture by Mid-Infrared and 13C Nuclear Magnetic Resonance Spectroscopies," Applied Spectroscopy, Vol. 58, No. 7, 2004, pp. 816-822. doi:10.1366/0003702041389238

[13] T. Kato, T. Fujimoto, A. Tsutsui, M. Tashiro, Y. Mitsutsuka and T. Machinami, "Identification of a Descrete Peroxide Dianion, $\mathrm{O}_{2}{ }^{2-}$, in a Two Sodium-(1,6-Anhydro$\beta$-Maltose) $)_{2}$-Peroxide Complex," Chemistry Letters, Vol. 39, No. 2, 2010, pp. 136-137. doi:10.1246/c1.2010.136

[14] T. Fujimoto, T. Kato, Y. Usui, O. Kamo, K. Furihata, K. Tsubono, T. Kato, T. Machinami and M. Tashiro, "Characterization of the Complex Formation of 1,6-Anhydro$\beta$-Maltose and Potassium Ions Using NMR Spectroscopy and Single-Crystal X-Ray Crystallography," Carbohydrate Research, Vol. 346, No. 13, 2011, pp. 1991-1996. doi:10.1016/j.carres.2011.06.017

[15] M. C. Burla, R. Caliandro, M. Camalli, B. Carrozzini, G. L. Cascarano, L. De Caro, C. Giacovazzo, G. Polidori and R. Spagna, "SIR2004: An Improved Tool for Crystal Structure Determination and Refinement," Journal of Applied Crystallography, Vol. 38, No. 2, 2005, pp. 381-388. doi:10.1107/S002188980403225X 